\title{
What's killing and maiming Canada's youth?
}

A cross Canada, injuries are the leading cause of death among our youth - those defined by the World Health Organization as being I2-24 years of age. The transition to adulthood, although smooth for some, can be full of danger: many take chances, act impulsively, overestimate their skills and abilities, are swayed by peer pressure or believe themselves invincible. Youths are less able than adults to gauge risk accurately, which leaves them more vulnerable to major trauma.

In 2003,1678 youths aged $15-24$ years died as a result of injury, which represents $73 \%$ of all deaths in this age group ${ }^{1}-$ 1 death in Canada for every 5 hours. Motor vehicle crashes account for the majority (about 60\%) of unintentional injuries. Even more disturbing, for every youth who dies from trauma, more than 10 have severe injuries often requiring 1 or more surgeries, prolonged hospital stays and rehabilitation..$^{1,2}$ The consequences of severe trauma, especially to the brain, are often so devastating and permanent that prevention is a far better investment than late interventions and supportive care.

This is not a new problem: a Io-year audit (1995-2004) of youth mortality in Nova Scotia found that injury (unintentional or not) accounted for $62 \%$ of all deaths. Nor is this a problem just in Canada: motor vehicle crashes continue to be the leading cause of death for 16-20-year-olds in the United States, ${ }^{3}$ Australia, New Zealand and most Western European countries.

We all appear to have become acclimatized to this public health epidemic. If 32 youths in Canada were dying each week from heart disease, influenza or meningitis, a huge outcry to stop this epidemic would be heard. Yet, deaths caused by injuries only seem to evoke distress and tears among parents and friends - and multiplying roadside crosses. So, why the deafening silence and lack of public attention to this epidemic?

A large number of observational studies comparing rates of motor vehicle trauma before and after major changes in public policy have provided compelling evidence about risk factors and effective changes to decrease motor vehicle-related trauma. A recent review by the American Academy of Pediatrics highlights risk factors such as young age at licensure; driver inexperience; overestimation of skills; risk-taking; number of young passengers; night-time driving; driving under the influence of alcohol, marijuana, prescription drugs or some combination thereof; lack of consistent use of seat belts; older or smaller cars; distractions such as cell-phone use; and being an unlicensed driver. ${ }^{3}$ In addition, youths with attentiondeficit-hyperactivity disorder who drive are $2-4$ times as likely to be involved in a crash as other youths. ${ }^{3}$

The most effective strategy appears to be a comprehensive 3-stage graduated driver's licensing system: a learner's permit, followed by an intermediate or provisional stage, and progression to a regular driver's permit. ${ }^{3}$ Beyond the delay to full li- censure, effective components include limits to night-time driving, restrictions to the number of passengers, and a requirement for novice drivers to remain crash- and violationfree before moving to the next level. ${ }^{3} \mathrm{~A}$ higher minimum drinking age has been directly associated with reductions in fatal youth crashes of $17 \%$; "zero tolerance" for alcohol, $24 \%{ }^{3}$ Stricter seat-belt policies and enforcement have also been proven to save the lives of young drivers. ${ }^{3}$

Will legislative changes be sufficient to combat this terrible epidemic? In our view, this is essential but insufficient but one component of the social change that is needed. We all bear some measure of responsibility for this ongoing tragedy. Physicians need to push for more comprehensive legislation and better enforcement based on the evidence. Physicians can counsel parents on the value of controlling access to cars, setting restrictions on use and passenger numbers, no alcohol use and seat-belt use, and also serve as role models for safe driving. Physicians, families, communities and politicians (especially those in rural areas) need to find creative ways for youth to socialize that do not necessitate them driving themselves and others to activities and events. Physicians need to help youths with attention-deficit-hyperactivity disorder and their parents to understand the enhanced risks and the importance of medications to improve attention.

Attitudes must change toward youthful driving. It should not be perceived as a right by youths and their parents, but a privilege that must be earned. It is time to stop ignoring the evidence, time to start conquering the youth injury epidemic.

\section{Noni MacDonald}

Pediatric Infectious Diseases

Natalie Yanchar

Pediatric General Surgery

Medical Director, IWK Trauma Care

IWK Health Centre

Dalhousie University

Halifax, NS

Paul C. Hébert

Editor-in-Chief, $C M A J$

for the CMAJ Editorial-Writing Team (Paul C. Hébert, Amir Attaran, Noni MacDonald, Ken Flegel), Ottawa, Ont.

\section{REFERENCES}

I. Statistics Canada. Causes of death, 2003. Cat. no. 84-208-XIE. Available: www .statcan.ca/bsolc/english/bsolc? catno=84-208-X (accessed 2007 Feb I3).

2. Canadian Institute for Health Information. National trauma registry: 2005 injury hospitalizations highlights report. National Trauma Registry: injury hospitalizations highlights report, 2004-2005. Ottawa: The Institute; 2007.

3. American Academy of Pediatrics Committees on Injury, Violence and Poison Prevention, and on Adolescence. The teen driver. Pediatrics 2006;118:2570-8I. 